REVIEW

\title{
Febrile seizures: an update
}

\section{Waruiru, R Appleton}

Arch Dis Child 2004;89:751-756. doi: 10.1136/adc.2003.028449

This review focuses on the latest knowledge and understanding of febrile seizures and outlines the more important issues in the management of children who present with an apparent "febrile seizure". It is not the remit of this paper to discuss the detailed management of febrile seizures. Throughout this review, the words "partial" and "focal" will be used interchangeably and the term "febrile seizure" (FS) will be used, reflecting the proposed changes in the terminology of seizures and epilepsies.'

See end of article for authors' affiliations

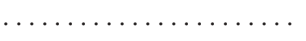

Correspondence to: Dr R Appleton, Royal Liverpool Children's Hospital (Alder Hey), Liverpool L12 2AP, UK richard.appleton@rlch-tr. nwest.nhs.uk

Accepted 28 February 2004
$\mathrm{T}$ here are two published operational definitions of FS. The National Institute of Health (NIH) consensus statement defines an FS as "an event in infancy or childhood usually occurring between three months and five years of age, associated with fever but without evidence of intracranial infection or defined cause for the seizure". ${ }^{2}$ This definition excludes seizures with fever in children who have previously had afebrile seizures. The International League Against Epilepsy (ILAE) defines an FS as "a seizure occurring in childhood after one month of age, associated with a febrile illness not caused by an infection of the central nervous system, without previous neonatal seizures or a previous unprovoked seizure, and not meeting criteria for other acute symptomatic seizures". ${ }^{3}$ The two definitions are very similar, differing only in the lower age limit (three versus one month respectively). Both definitions do not exclude children with prior neurological impairment and neither provides a specific temperature criterion nor defines a "seizure". The three components, age, fever, and a seizure, are critical elements in the definition.

\section{AGE}

Most febrile seizures occur between 6 months and 3 years of age with the peak incidence at 18 months. ${ }^{4-6}$ Approximately $6-15 \%$ occur after 4 Regardless of the population, most data support the unique age specificity of the maturing brain's sensitivity to fever. Although the mechanism of this increased susceptibility is unclear, animal models suggest that there is enhanced neuronal excitability during the normal brain maturation. ${ }^{7}$

\section{FEVER}

By definition there has to be a febrile illness or certainly fever. Many febrile seizures occur early in the illness and may be the presenting feature, years, and onset after 6 years is unusual. but others occur during or after the onset of fever, ${ }^{89}$ observations that may in part reflect the difficulties in both taking and accurately recording the temperature of young children. There are no data to support the rate of temperature rise as being more important than the peak temperature achieved. ${ }^{10}{ }^{11}$ It is also unclear whether there may be a lower limit of fever under which it would be difficult to make a diagnosis of an $\mathrm{FS}^{12}$ with some studies citing $>38^{\circ} \mathrm{C}$ and others, $>38.4^{\circ} \mathrm{C}$. It is possible that the peak of the fever may be related to recurrent $\mathrm{FS}^{8}{ }^{81}{ }^{13}$ Children with FS with a relatively low fever $\left(<38.9^{\circ} \mathrm{C}\right)$ tend to present with an initial seizure that has focal features or is repeated within the same febrile illness. ${ }^{14}$ Antipyretics have not been shown to reduce the risk of febrile seizures, ${ }^{15}{ }^{16}$ suggesting that it may not be the fever itself that causes an FS. Animal studies suggest a possible role of endogenous pyrogens such as interleukin 1 that, by influencing neuronal excitability, may link fever and seizure activity. ${ }^{17}$ Preliminary studies in children appear to support the hypothesis that the cytokine network is activated and may have a role in the pathogenesis of $\mathrm{FS},{ }^{18}{ }^{19}$ but the precise pathological or clinical significance of these observations is as yet unclear.

\section{SEIZURE}

Clearly, FS must have a clinical component-a "seizure". The NIH Consensus definition uses the vague term, "event" rather than seizure. ${ }^{2}$ Other episodes or clinical events that may typically mimic an epileptic (and specifically a tonic-clonic) seizure, including rigors, syncope, reflex anoxic seizures, breath holding spells, impaired consciousness, and apnoea may also be associated with any febrile illness and must be excluded by taking a careful history. It is possible that a number of children with FS reported in the literature may in fact have had one of these other paroxysmal, non-epileptic disorders and not FS.

Febrile seizures are typically divided into two types, "simple" and "complex". A simple FS comprises of generalised tonic-clonic activity without focal features, of less than 10 minutes duration, without a recurrence in the subsequent 24 hours and resolving spontaneously. Complex febrile seizures are defined on one or more of the following features: a partial (focal) onset or showing focal features during the seizure,

Abbreviations: $\mathrm{CT}$, computed tomography; EEG, electroencephalogram; FS, febrile seizure; GEFS+, generalised epilepsy and febrile seizures plus; ILAE, International League Against Epilepsy; LP, lumbar puncture; MRI, magnetic resonance imaging; MTLE, mesial temporal epilepsy; MTS, mesial temporal sclerosis; TLE, temporal lobe epilepsy 
prolonged duration (greater than 10-15 minutes), and recurrent within 24 hours or within same febrile illness. ${ }^{3} 4820$ The term "complex" may in the future be replaced by "complicated" in light of the new proposed seizure classification in which the words simple and complex in the ILAE classification of partial seizures may disappear. ${ }^{1}$ Arguably, the most appropriate approach would be to replace either term"complex" or "complicated", with the precise description of the seizure and specify whether the FS was "prolonged", "focal", or "multiple".

\section{THE INCIDENCE OF FEBRILE SEIZURES}

Population studies in Western Europe and the USA report a cumulative incidence of $2-5 \%{ }^{20}{ }^{21}$ The incidence elsewhere in the world varies between $5-10 \%$ (India), 8.8\% (Japan), and $14 \%$ (Guam). ${ }^{5}$ Data from developing countries are limited, possibly because it may be very difficult to differentiate simple FS from acute symptomatic (infective) seizures, particularly if due to falciparum malaria infection. ${ }^{22}$ Between $9 \%$ and $35 \%$ of all first FS are complex, ${ }^{142123}$ and it may be important to establish this at presentation because children with prolonged or multiple FS are at increased risk of developing unprovoked seizures. ${ }^{921}{ }^{24}$ The wide variation in the proportion of the initial FS being complex (9-35\%), may reflect the difficulties in differentiating simple from complex FS, and perhaps even differentiating FS from afebrile seizures. Finally, although complex FS represent a small fraction of all FS, febrile status epilepticus (that is, a complex FS) accounts for $25 \%$ of all episodes of status epilepticus in children. ${ }^{25}$

\section{RISK FACTORS What are the risk factors for developing a febrile seizure?}

Febrile seizures occur when a susceptible child of a critical age has a fever. The fever is typically higher than in control children with a similar illness, although the seizure does not always occur at the same time as the peak temperature or necessarily at the onset of fever. ${ }^{26}$ The most consistently identified risk factor for FS is the presence of a close family history (within first degree relatives) of FS. The more relatives affected, the greater the risk. In cohorts of children with FS, the risk that siblings will have an FS is $10-45 \% .{ }^{27}$ Many studies have also found that the risk may be increased by an underlying brain disorder. Premature birth, delayed discharge from the neonatal intensive care unit, and developmental delay are potential markers for suboptimal brain function, but there is conflicting evidence definitively linking these factors and FS, ${ }^{16} 21_{24}^{28-31}$ which may in part reflect whether the study was hospital or community based. Other studies suggest an increased risk with exposure to infectious illnesses such as human herpesvirus-6. ${ }^{32}$ Any viral or bacterial illness may provoke FS, and this is also (rarely) true for immunisation. ${ }^{33}{ }^{34}$ However, these factors are more provocation, rather than risk factors. Generally, at least 50\% of children who present with febrile seizures will have no identified risk factors.

\section{What are risk factors for recurrence?}

Most children with FS do not experience further FS, but one third will; age would appear to be the single, strongest, and most consistent risk factor. ${ }^{8} 92021356$ More than half of the risk is realised during the first year after the initial FS and over $90 \%$ recur within two years. A family history of febrile seizures (but not epilepsy) in a first degree relative, is associated with an increased risk of recurrence. ${ }^{8357}$ Recurrences appear to be more likely in children whose initial FS occurred with a relatively low fever. ${ }^{813}{ }^{13}$ Multiple initial seizures occurring during the same febrile episode also appear to be associated with an increased risk of recurrence. ${ }^{38}$ Recurrent FS tend to be prolonged if the initial FS was prolonged. ${ }^{14}$ However, febrile status epilepticus in an otherwise normal child does not appear to significantly increase the risk for further febrile seizures or the development of epilepsy..$^{25}$

\section{What are the risk factors for developing epilepsy?}

Accumulating epidemiological evidence indicates that FS are the most common recognised antecedent for epilepsy in childhood, although the precise risk of developing epilepsy after febrile seizures is unclear. Following a first FS, $2-4 \%$ of children will experience at least one unprovoked seizure, a risk four times that in the general population, ${ }^{4} 20$ and most of these children will subsequently develop epilepsy. Viewed from a different perspective, between 13\% and 19\% of children with afebrile seizures will have had one or more previous FS. ${ }^{40}$ Factors that consistently increase the risk for developing unprovoked seizures (epilepsy) following FS, include a family history of epilepsy, complex features, and the presence of early onset neurodevelopmental abnormalities. $^{441}$ These factors are different to the risk factors associated with recurrent FS, thereby supporting the argument that FS are distinct from unprovoked seizures. ${ }^{42}{ }^{43}$ In view of the advances being made in identifying genes relevant to epilepsy syndromes including generalised epilepsy and febrile seizures "plus" (GEFS+), ${ }^{44}$ the current approach in evaluating the risk of epilepsy following FS is based on specific epilepsy syndromes. These may be arbitrarily divided into two major groups: the idiopathic generalised epilepsies, recognised to have a strong but complicated genetic basis; and the partial (focal) epilepsies (including mesial temporal lobe epilepsy, MTLE), currently considered to have a definite, though weaker genetic basis. MTLE appears to be associated with prolonged and/or focal FS in retrospective studies, ${ }^{41}$ but evidence is emerging that MTLE may also be genetically determined. This emphasises the importance of taking a detailed family history in any child who presents with both febrile and afebrile seizures.

\section{THE GENETICS OF FEBRILE SEIZURES}

The literature describing the genetics of FS is extensive, continually expanding, and is complicated, reflecting the complexity of the disorder. The risk of developing FS is higher in some families than in others. ${ }^{16} 384546$ A positive family history for FS can be elicited in $25-40 \%$ of patients with febrile seizures ${ }^{47}$ and the reported frequency in siblings of children with FS has ranged from $9 \%$ to $22 \%$. Studies showing a higher concordance rate in monozygotic rather than in dizygotic twins also support a genetic contribution. Familial clustering studies indicate a doubling of risk in children when both parents, rather than one parent had FS. Although there is clear evidence for a genetic basis of FS, the mode of inheritance is unclear. Most convincing evidence has emerged from linkage studies with reported linkages on numerous chromosomes $\left(2 q_{,}{ }^{48} 5 q^{,{ }^{49}} 5,{ }^{50} 8 q^{51} 19 p^{52}\right.$ and $19 q^{53}$ ), with the strongest linkage on chromosome $2 q$ and specifically, linkage to the genes responsible for sodium channel receptors-and specifically a mutation in the alpha $(\alpha)$ subunit of the first neuronal sodium channel gene (SCNIA). The linkage on chromosomes $2 \mathrm{q}$ and $19 \mathrm{q}$ associated with the phenotype of febrile seizures, generalised epilepsy (tonic-clonic, absence, and myoclonic), and a continuation of febrile seizures ( $>5$ years of age) (GEFS+), ${ }^{44} 54$ shows evidence of sodium channel involvement. There is currently no evidence that any of these loci have any role in the more common, "simple" FS, with the possible exception of the chromosome 5 locus reported in the Japanese population. ${ }^{49}$ 
Clearly, febrile seizures are an extremely heterogeneous condition with a complicated and, as yet, unclear pathophysiological and genetic basis. ${ }^{55}$

\section{FEBRILE SEIZURES AND TEMPORAL LOBE EPILEPSY (TLE)}

This remains one of the most controversial issues in epilepsy. Studies have approached the question from different perspectives and not unexpectedly, the results remain unclear and often contradictory. ${ }^{56}$ Retrospective studies from tertiary centres report that as many as $40 \%$ of adults with intractable temporal lobe epilepsy give a history of complex (specifically prolonged) FS in childhood..$^{57-59}$ A recent study by Trinka and colleagues $^{41}$ found a strong association between prolonged and focal FS and the development of TLE. These findings are supported by magnetic resonance imaging (MRI) studies showing hippocampal sclerosis and atrophy in patients who experienced prolonged FS in childhood. ${ }^{60-63}$ The selection of children and the timing of neuroimaging have varied between studies, making evaluation of any potential evolving process difficult. A specific study employing MRI as a research tool, that was undertaken within 48 hours of a prolonged FS (including febrile status epilepticus), showed evidence of temporal lobe (hippocampal) oedema. ${ }^{64}$ Subsequent follow up imaging within 12 months in this population showed resolution of the oedema and did not show any hippocampal atrophy or mesial temporal sclerosis (MTS) in the previously swollen temporal lobes. ${ }^{65}$ The identification of hippocampal atrophy in patients with a previous history of prolonged FS does not necessarily prove a causal relation, and in the study by Kuks and colleagues, ${ }^{60} 64 \%$ of 107 patients with hippocampal atrophy and MTS had no history of FS.

Early histological reports suggested a possible causal relation between prolonged childhood FS and MTS.66 ${ }^{67}$ However, more recent neuropathological data from 33 children with refractory TLE, with and without a history of preceding risk factors for TLE, showed cortical dysplasia in 21 patients $(66 \%)$, including $73 \%$ of patients (11/15) with a history of $\mathrm{FS}^{6}{ }^{68}$ Cortical dysplasia (which typically has an onset in early fetal life), rather than FS, could arguably explain the development of late and intractable epilepsy. Finally, animal data support the hypothesis that, over time, prolonged FS may enhance hippocampal excitability. ${ }^{69-71}$

In summary, most retrospective analyses from tertiary (often epilepsy surgery) centres have suggested a definite, though inconstant, association between TLE and early, prolonged FS, with, generally, an excellent response to surgical treatment. ${ }^{58} 59$ However, it is clearly possible that these centres may have overestimated the frequency and therefore the impact of an uncommon or rare association.

In contrast, prospective and controlled, population based studies have failed to confirm this apparent association. ${ }^{40}{ }^{42}$ It has been argued that prospective studies would have to be much larger and conducted over a longer period, to identify the small group that develop complex partial (focal) seizures of temporal lobe origin. This is because hippocampal atrophy or MTS may not be demonstrable until late childhood, adolescence, or early adulthood-although MTS has occasionally been shown in children as young as 4 years of age. ${ }^{72}$ It is possible that this was already present (and responsible for the initial, prolonged FS), as MRI would not normally be undertaken at the time of the initial FS. A recent, prospective MRI study of 329 unselected patients with FS failed to show any hippocampal injury and reasonably concluded that there may be no causal relation between FS and MTS. ${ }^{73}$ Although there is some evidence that the severity or extent of hippocampal atrophy may be directly related to either frequent secondarily generalised tonic-clonic seizures, ${ }^{74}$ or the duration of epilepsy, ${ }^{75}$ this may simply reflect the effect of frequent afebrile (that is, epileptic) seizures in and throughout childhood, rather than a prolonged FS in infancy.

Current opinion supports an association between prolonged FS and pre-existing lesions within the temporal lobe-and that this may subsequently facilitate the development of hippocampal atrophy. ${ }^{76}$ In addition, the contradictory findings obtained from epidemiological, neuroimaging, and pathological studies would also suggest that the association of complex FS with hippocampal atrophy and TLE reflects complex interactions with genetic or environmental factors (or both), which may subsequently facilitate the development of TLE. This increased susceptibility is likely to be multifactorial but may involve cytokines, and specifically interleukin 1.

\section{OUTCOME OF FEBRILE SEIZURES Epilepsy}

The risk of epilepsy, and specifically, MTLE, has been discussed previously.

\section{Neurodevelopment}

Most population based studies have shown no obvious association between simple or complex FS, including febrile status, and the later development of neurological deficits (for example, hemiplegia), overall cognitive functioning, or specific memory impairment. ${ }^{24} 77$ Not surprisingly, those children who develop late onset and drug resistant focal seizures (specifically with MTLE) have been shown to have significant cognitive and psychosocial difficulties. It is likely that this is related primarily to subsequent frequent afebrile focal seizures, possibly on a background of a pre-existing temporal (hippocampal) abnormality, rather than early complex FS.

\section{Mortality}

Most population studies have shown no increased risk or incidence of mortality in children with $\mathrm{FS}^{79}{ }^{80}$ including febrile status epilepticus, and excluding infections of the central nervous system (CNS). In addition there does not appear to be any association between FS and sudden infant death syndrome..$^{81}$ This is clearly very important and should be emphasised in discussions about FS with families. ${ }^{82}$

\section{EVALUATION OF THE CHILD WITH A FEBRILE SEIZURE}

A detailed history including family history of FS, epilepsy, and sudden deaths in the family is mandatory. Examination looking for evidence of meningitis, underlying neurological deficit, asymmetry, or stigmata of a neurocutaneous or metabolic disorder, and measuring the head circumference may be important and informative. A number of questions need to be addressed when faced with a child who has had a first or subsequent FS.

\section{Was it a seizure and not a rigor, reflex anoxic seizure,} or other non-epileptic event?

This can only be answered by the history that may be difficult if, as is usual, the witnesses, including the child's carers were frightened by the episode. It is important although not always easy, to determine if the seizure could have been provoked by fever in a child already known, or suspected to have epilepsy.

\section{Was it febrile-and if so, where is the infection?}

This may be difficult for reasons stated earlier. In addition pyrexia may follow an afebrile tonic-clonic seizure, although this will rarely exceed $38^{\circ} \mathrm{C}$. Ear, throat, lower respiratory, urinary tract, and a CNS infection should be considered as possible sources of any febrile illness. Routine blood tests are not recommended unless where clinically indicated. ${ }^{83} 84$ 
Interestingly, the risk of bacteraemia would appear to be the same in children with fever with or without simple febrile seizures. ${ }^{85}$ Each child must therefore be evaluated individually and carefully.

\section{Is there any possibility of meningitis, encephalitis, or an encephalopathy?}

It is clearly important to consider and, where appropriate, exclude meningitis or encephalitis in any child who presents with FS. Consequently, one of the most common decisions is whether a lumbar puncture (LP) is necessary. The estimated incidence of meningitis in children who present with an apparent FS is $2-5 \% .^{83}{ }^{86-90}$ The yield of positive findings from LP varies between studies, and is generally low in the absence of risk factors including focal seizures, and suspicious clinical findings..$^{83} 9192$ Deciding whether a child has meningitis will be easier in the older child ( $>2$ years) where there may be meningism or photophobia. In children $<2$ years of age this may be more difficult and there should be a low threshold for considering meningitis or encephalitis (specifically herpes simplex type 1), particularly in the following situations: ${ }^{83} 849394$

- Where there is a history of irritability, decreased feeding, or lethargy

- Where the seizure was prolonged, focal, or multiple FS occurred as part of the same febrile illness

- Any physical signs of meningitis/encephalitis

- Prolonged post-ictal altered consciousness or neurological deficit

- Pretreatment with oral antibiotics.

In these situations an LP with simultaneous blood and cerebrospinal fluid (CSF) glucose levels should be undertaken unless there are specific contraindications, ${ }^{12} 8393-95$ despite recent comments. ${ }^{96}$ Previous practice guidelines recommend that a lumbar puncture be strongly considered in almost all infants $<12$ months with FS. ${ }^{1283849397}$ or $<6$ months. ${ }^{98}$ Between 12-18 months of age the symptoms and signs of meningitis may also be subtle and consequently, an LP should be considered in a child presenting with FS. ${ }^{83} 9397$

\section{Could there be an underlying static or progressive abnormality?}

Obviously, information from the history and examination may help to address this issue. Unless the child has an unexplained encephalopathy there is no indication to undertake an early electroencephalogram (EEG), irrespective of whether the FS was simple or complex. Recurrent simple or complex FS also do not justify an EEG, as it is of no use in identifying a structural abnormality or in predicting recurrent FS or the development of epilepsy. ${ }^{99}$ Neuroimaging is not indicated in a child with a simple $\mathrm{FS}^{83}{ }^{83}$ and not every child with a complex FS requires a brain scan, although this will clearly depend on the clinical situation. Neuroimaging should be considered in children with FS who are also found to have the following:

- Micro/macrocephaly, a neurocutaneous syndrome or preexisting neurological deficit

- Post-ictal neurological deficit persisting for more than a few hours following the FS

- Recurrent complex febrile seizures and particularly where there was any doubt whether the seizures were febrile in origin. ${ }^{12} 8494$

Magnetic resonance imaging is superior to computerised tomography (CT), specifically for those situations where there may be an underlying inflammatory (for example, herpes simplex or Rasmussen's encephalitis) or structural (for example, cerebral dysgenesis, tumours, and vascular malformations) cause.

Rarely, a febrile seizure may be the first sign of a metabolic disease (for example, a mitochondrial cytopathy including "Leigh's syndrome" or progressive neuronal degeneration of childhood), an inflammatory disorder (for example, Rasmussen's encephalitis), or one of the more malignant epilepsy syndromes (for example, severe myoclonic epilepsy in infancy). The possibility of a metabolic disorder may be suggested from the history and examination (for example, developmental regression, family history of sudden death in infancy/childhood, failure to thrive, hepatosplenomegaly, micro- and macrocephaly) and, if present, should prompt referral to a paediatric neurologist.

\section{Should diazepam be used for further febrile seizures or febrile episodes?}

For children who appear to have a very low threshold for FS with any febrile episode and particularly if the seizures are recurrent and prolonged, there is the option of using rectal diazepam in two situations:

- Whenever the child is febrile and before the child starts seizing $^{94} 100101$

- As soon as the child starts seizing.

There is conflicting evidence on the effectiveness of intermittent diazepam in preventing recurrent seizures, although the general consensus is that it is likely to be effective. ${ }^{94}{ }^{100-103}$ However, the early use of oral ${ }^{102}$ or rectal ${ }^{103}$ diazepam (before the child starts seizing) may result in drowsiness and ataxia that might interfere with the carers' and doctors' ability to distinguish a "benign" febrile illness from a potentially more serious febrile illness, specifically meningitis/encephalitis or a structural brain lesion. The decision to use rectal diazepam should be based on a number of factors: the balance between the potential benefits and risks, the wishes and abilities of the child's carers, and the child's frequency and pattern of febrile illnesses and type of FS.

\section{Is prophylaxis indicated?}

Complex FS, particularly if prolonged, and an abnormal neurological status are recognised risk factors for the development of later epilepsy. ${ }^{20}{ }^{39}$ However, a child's neurological status should not influence whether prophylactic antiepileptic drugs are indicated. There is no convincing evidence and therefore no justification that the regular use of prophylactic antiepileptic medication with phenobarbitone, phenytoin, sodium valproate, or carbamazepine ${ }^{101}$ 104-106 significantly reduces the risk of either further FS or the development of late epilepsy. These reports and those from the Royal College of Paediatrics and Child Health ${ }^{93}$ and the American Academy of Paediatrics ${ }^{100}$ do not recommend the use of prophylactic antiepileptic medication in children with either simple or complex FS.

What information should be given to the family? Facts and advice should be both verbal and written, explaining what an FS is, that they are common, that recurrences are unlikely, and that the risk of brain damage and later epilepsy are very rare. ${ }^{107}$ They should be reassured that there is no evidence that any child has ever died as a result of an FS. ${ }^{79}{ }^{80}$ Advice should also include what to do if their child has a febrile illness and what to do if their child has a further FS, and specifically that an ambulance should be called if the tonic-clonic seizure has lasted 5-10 or more minutes and shows no signs of stopping. 


\section{ACKNOWLEDGEMENTS}

Most of the above comments on the evaluation and management of the child with FS have been derived predominantly from "expert", consensus statements and guidelines, limited high quality scientific research, and the authors' clinical experience. Further details and supporting information can be found from numerous (and still expanding) sources; for example, Cochrane Central Register of Controlled Trials, NeLH (National Electronic Library of Health) Guidelines Finder, Scottish Intercollegiate Guidelines Network (SIGN), RCPCH Guideline and Clinical Effectiveness Publications, PIER Guidelines database.

The authors are grateful to the Evidence Base Child Health Unit, Alder Hey Children's Hospital (Jean Craig and Leanne Jones), and to the Cochrane Epilepsy Group, Clinical Science Centre for Research and Education, University of Liverpool (Vicki Sparkes and Alison Beamond) for their assistance and advice in the preparation of this manuscript.

\section{Authors' affiliations}

C Waruiru, R Appleton, The Roald Dahl EEG Unit, Department of Neurology, Royal Liverpool Children's Hospital (Alder Hey), Liverpool, UK

\section{REFERENCES}

1 Engel J Jr. A proposed diagnostic scheme for people with epileptic seizures and with epilepsy: report of the ILAE task force on classification and terminology. Epilepsia 2001;42:796-803.

2 Freeman JM. Febrile seizures: a consensus of their significance, evaluation, and treatment. Consensus development conference of febrile seizures. 1980 National Institute of Health. Pediatrics 1980;66:1009-12.

3 ILAE. Guidelines for epidemiologic studies on epilepsy. Epilepsia 1993;34:592-6.

4 Annegers JF, Hauser WA, Shirts SB, et al. Factors prognostic of unprovoked seizures after febrile convulsions. N Engl J Med 1987;316:493-8.

5 Hauser WA. The prevalence and incidence of convulsive disorders in children. Epilepsia 1994;35(suppl 2):S1-6.

6 Offringa M, Hazebroek-Kampschreur AAJM, Derksen-Lubsen G. Prevalence of febrile seizures in Dutch school children. Paediatr Perinat Epidemiol 1991;5:181-8.

7 Jensen FE, Sanchez RM. Why does the developing brain demonstrate heightened susceptibility to febrile and other provoked seizures. In: Baram TZ, Shinnar S, eds. Febrile seizures. San Diego: Academic Press, 2002:153-68.

8 Berg AT, Shinnar S, Darefsky AS, et al. Predictors of recurrent febrile seizures. Arch Pediatr Adolesc Med 1997;151:371-8.

9 Berg AT, Shinnar S, Hauser WA, et al. A prospective study of recurrent febrile seizures. N Engl J Med 1992;327:1122-7.

10 Berg AT. Are febrile seizures provoked by a rapid rise in temperature. Am J Dis Child 1993;147:1101-3.

11 Minchom PE, Wallace S. Febrile convulsions: electroencephalographic changes related to rectal temperature. Arch Dis Child 1984;59:371-3.

12 Shinnar S, Glauser TA. Febrile seizures. J Child Neurol 2002;17/suppl 11):S44-52.

13 El-Radhi AS, Withana K, Banajeh S. Recurrence rate of febrile convulsion related to the degree of pyrexia during the first attack. Clin Pediatr 1986;25:311-13.

14 Berg AT, Shinnar S. Complex febrile seizures. Epilepsia 1996;37:126-33.

15 Camfield PR, Camfield CS, Shapiro SH, et al. The first febrile seizureantipyretic instruction plus either phenobarbital or placebo to prevent recurrence. J Pediatr 1980;97:16-21.

16 Bethune P, Gordon K, Dooley J, et al. Which child will have a febrile seizure. Am J Dis Child 1993; 147:35-9.

17 Gatti S, Vezzani A, Barffai T. Mechanisms of fever and febrile seizures: putative role of the interleukin-1 system. In: Baram TZ, Shinnar S, eds. Febrile seizures. San Diego: Academic Press, 2002:169-88.

18 Virta M, Hurme M, Helminen M. Increased plasma levels of pro- and antiinflammatory cytokines in patients with febrile seizures. Epilepsia 2002;43:920-3

19 Haspolat S, Mihci E, Coskum M, et al. Interleukin-1 beta, tumour necrosis factor-alpha, and nitrite levels in febrile seizures. J Child Neurol 2002; 17:749-51.

20 Nelson KB, Ellenberg JH. Predictors of epilepsy in children who have experienced febrile seizures. N Engl J Med 1976;295:1029-33.

21 Verity CM, Butler NR, Golding J. Febrile convulsions in a national cohort followed up from birth. I-prevalence and recurrence in the first five years of life. BMJ 1985;290:1307-10

22 Waruiru CM, Newton CRJC, Forster D, et al. Epileptic seizures and malaria in Kenyan children. Trans R Soc Trop Med Hyg 1996;90:152-5.

23 Forsgren $L$, Sidenvall R, Blomquist HK, et al. A prospective incidence study of febrile convulsions. Acta Paediatr Scand 1990;79:550-7.

24 Verity CM, Butler NR, Golding J. Febrile convulsions in a national cohort followed up from birth. II-Medical history and intellectual ability at 5 years of age. BMJ 1985;290:1311-14.

25 Maytal J, Shinnar S. Febrile status epilepticus. Pediatrics 1990;86:611-16.
26 Berg AT, Shinnar S, Shapiro ED, et al. Risk factors for a first febrile seizure: a matched case-control study. Epilepsia 1995;36:334-41.

27 Van Esch A, Steyerberg EW, Van Duijn CM, et al. Prediction of febrile seizures in siblings: a practical approach. Neuropediatrics 1998; 157:340-4

28 Greenwood R, Golding J, Ross E, et al. Prenatal and perinatal antecedents of febrile convulsions and afebrile seizures: data from a national cohort study. Paediatr Perinat Epidemiol 1998;12(suppl 1):76-95.

29 Vestergaard M, Basso O, Henriksen TB, et al. Risk factors for febrile convulsions. Epidemiology 2002;13:282-7.

30 Huang CC, Wang ST, Chang YC, et al. Risk factors for a first febrile convulsion in children: a population study in southern Taiwan. Epilepsia 1999;40:719-25.

31 Nelson KB, Ellenberg JH. Prenatal and perinatal antecedents of febrile seizures. Ann Neurol 1990;27:127-31.

32 Hall CB, Long CE, Schnabel KC, et al. Human herpesvirus- 6 infection in children. N Engl J Med 1994;331:432-8.

33 Barlow WE, Davis RL, Glasser JW, et al. The risk of seizures after receipt of whole-cell pertussis or measles, mumps, and rubella vaccine. N Engl J Med 2001;345:656-61.

34 Hirtz DG, Nelson KB, Ellenberg JH. Seizures following childhood immunisations. J Pediatr 1983;102:14-18.

35 Al-Eissa YA. Febrile seizures: rate and risk factors of recurrence. J Child Neurol 1995; 10:315-19.

36 Berg AT, Shinnar S, Hauser WA, et al. Predictors of recurrent febrile seizures: a metaanalytic review. J Pediatr 1990;1 16:329-37

37 Knudsen FU. Recurrence risk after a first febrile seizure and effect of shortterm diazepam prophylaxis. Arch Dis Child 1985;60:1045-9.

38 Offringa M, Bossuyt PMM, Lubsen J, et al. Risk factors for seizure recurrence in children with febrile seizures: a pooled analysis of individual patient data from five studies. J Pediatr 1994; 124:574-84.

39 Verity CM, Golding J. Risk of epilepsy after febrile convulsions: a national cohort study. BMJ 1991:303:1373-6.

40 Camfield P, Camfield C, Gordon K, et al. What types of epilepsy are preceded by febrile seizures? A population-based study of children. Dev Med Child Neurol 1994:36:887-92.

41 Trinka E, Unterrainer J, Haberlandt UE, et al. Childhood febrile convulsions - which factors determine the subsequent epilepsy syndrome? A retrospective study. Epilepsy Res 2002;50:283-92.

42 Berg AT, Shinnar S, Levy SR, et al. Childhood-onset epilepsy with and without preceding febrile seizures. Neurology 1999;53:1742-8.

43 Berg AT. Febrile seizures and epilepsy: the contribution of epidemiology. Paediatr Perinatal Epidemiol 1992;6:145-52.

44 Singh R, Scheffer IE, Crossland K, et al. Generalized epilepsy with febrile seizures plus: a common childhood-onset genetic epilepsy syndrome. Ann Neurol 1999:45:75-81.

45 Fukuyama Y, Kagawa K, Tanaka K. A genetic study of febrile convulsions. Eur Neurol 1979;18:166-82.

46 Tsuboi T, Okada S. Exogenous causes of seizures in children: a population study. Acta Neurol Scand 1985;1:107-13.

47 Hauser WA, Annegers JF, Anderson VE, et al. The risk of seizure disorders among relatives of children with febrile convulsions. Neurology 1985;35:1268-73.

48 Baulac S, Gourfinkel-An I, Picard F, et al. A second locus for familial generalized epilepsy with febrile plus maps to chromosome 2q21-q33. Am J Hum Genet 1999:65:1078-85.

49 Nakayama J, Hamano K, Iwaski N, et al. Significant evidence for linkage of febrile seizures to chromosome 5q1 4-q15. Hum Mol Genet 2000;9:87-91.

50 Wallace RH, Scheffer IE, Barnett S, et al. Neuronal sodium-channel $\alpha$ ]subunit mutations in generalized epilepsy with febrile seizures plus. Am J Hum Genet 2001;68:859-65

51 Wallace RH, Berkovic SF, Howell RA, et al. Suggestion of a major gene for familial febrile convulsions mapping to 8q13-21. J Med Genet 1996;33:308-12.

52 Johnson EW, Dubovsky J, Rich SS, et al. Evidence for a novel gene for familial febrile convulsions, FEB2, linked to chromosome 19p in an extended family from the Midwest. Hum Mol Genet 1998;7:63-7.

53 Wallace RH, Wang DW, Singh R, et al. Febrile seizures and generalized epilepsy associated with a mutation in the $\mathrm{Na}$--channel beta 1 subunit gene SCN1B. Nat Genet 1998;19:366-70.

54 Scheffer IE, Berkovic SF. Generalised epilepsy with febrile seizures plus: a genetic disorder with heterogeneous clinical phenotypes. Brain 1997; 120:479-90.

55 Rachacho LJ, Mclachlan RS, Ebers GC, et al. Evidence favouring genetic heterogeneity for febrile convulsions. Epilepsia 2000;41:132-9.

56 Liu Z, Mikati M, Holmes G. Mesial temporal sclerosis: pathogenesis and significance. Pediatr Neurol 1995; 12:5-16.

57 Cendes F, Andermann F, Dubeau F, et al. Early childhood prolonged febrile convulsions, atrophy and sclerosis of mesial structures, and temporal lobe epilepsy: an MRI volumetric study. Neurology 1993;43:1083-7.

58 Abou-khalil B, Andermann E, Olivier A, et al. Temporal lobe epilepsy after prolonged febrile convulsions: excellent outcome after surgical treatment. Epilepsia 1993:34:878-83.

59 French JA, Williamson PD, Thadani VM. Characteristics of medial temporal lobe epilepsy: I. Results of history and physical examination. Ann Neurol 1993;34:774-80.

60 Kuks JBM, Cook MJ, Stevens JM, et al. Hippocampal sclerosis in epilepsy and childhood febrile seizures. Lancet 1993:342:1391-4.

61 Grunewald RA, Farrow T, Vaughan P, et al. A magnetic resonance study of complicated early childhood convulsion. I Neurol Neurosurg Psychiatry 2001;71:638-42. 
62 Nohria V, Lee N, Tien RD, et al. Magnetic resonance imaging evidence of hippocampal sclerosis in progression: a case report. Epilepsia 1994;35:1332-6.

63 Van Landingham KE, Heinz ER, Cavazas JE, et al. Magnetic resonance imaging evidence of hippocampal injury after prolonged focal febrile convulsions. Ann Neurol 1998;43:413-26.

64 Scott RC, Gadian DG, King MD, et al. Magnetic resonance imaging findings within 5 days of status epilepticus in childhood. Brain 2002;125:1951-9.

65 Scott RC, King MD, Gadian DG, et al. Hippocampal abnormalities after prolonged febrile convulsion: a longitudinal MRI study. Brain 2003; 126:2551-7

66 Falconer MA, Serafetinides EA, Corsellis JA. Etiology and pathogenesis of temporal lobe epilepsy. Arch Neurol 1964;10:233-48.

67 Sagar HJ, Oxbury JM. Hippocampal neuron loss in temporal lobe epilepsy: correlation with early childhood convulsions. Ann Neurol 1987;22:334-40.

68 Porter BE, Judkins AR, Clancy RR, et al. Dysplasia: a common finding in intractable pediatric temporal lobe epilepsy. Neurology 2003:61:365-8.

69 Chen K, Aradi I, Thon N, et al. Persistently modified h-channels after complex febrile seizures convert the seizure-induced enhancement of inhibition to hyperexcitability. Nat Med 2001;7:331-7.

70 Chen K, Baram TZ, Soltesz I. Febrile seizures in the developing brain result in persistent modification of neuronal excitability in limbic circuits. Nat Med 1999;5:888-94

71 Dube C, Chen K, Eghbal-Ahmadi M, et al. Prolonged febrile seizures in the immature rat model enhance hippocampal excitability long term. Ann Neurol 2000:47:336-44.

72 Murakami N, Ohno S, Oka E, et al. Mesial temporal lobe epilepsy in childhood. Epilepsia 1996;37(suppl 3):S52-6

73 Tarkka R, Paakko E, Phytinen J, et al. Febrile seizures and mesial temporal sclerosis: no association in a long-term follow-up study. Neurology 2003;60:215-18.

74 Van Paesschen W, Connelly A, King MD, et al. The spectrum of hippocampal sclerosis: a quantitative magnetic resonance imaging study. Ann Neurol 1997:41:41-51.

75 Theodore WH, Bhatia S, Hatta J, et al. Hippocampal atrophy, epilepsy duration, and febrile seizures in patients with partial seizures. Neurology 1999;52:132-6

76 Mitchell TV, Lewis DV. Do prolonged febrile seizures injure the hippocampus? Human MRI Studies. In: Baram TZ, Shinnar S, eds. Febrile seizures. San Diego: Academic Press, 2002:103-21

77 Ellenberg JH, Nelson KB. Febrile seizures and later intellectual performance. Arch Neurol 1978;35:17-21.

78 Verity CM, Greenwood R, Golding J. Long-term intellectual and behavioura outcome of children with febrile convulsions. N Engl J Med 1998;338:1723-38.

79 Callenbach PM, Westendorp RG, Geerts AT, et al. Mortality risks in children with epilepsy: the Dutch study of epilepsy in childhood. Pediatrics 2001;107:1259-63.

80 Camfield CS, Camfield PR, Veugelers PJ. Death in children with epilepsy: a population-based study. Lancet 2002;359:1891-5

81 Vestergaard $M$, Basso $O$, Henrikesen TB, et al. Febrile convulsions and sudden infant death syndrome. Arch Dis Child 2002;86:125-6.

82 Baumer JH, David TJ, Valentine SJ, et al. Many parents think their child is dying when having a first febrile convulsion. Dev Med Child Neurol 1981;23:462-4.

83 AAP. Practice parameter: the neurodiagnostic evaluation of the child with o first simple febrile seizure. American Academy of Pediatrics. Provisional
Committee on Quality Improvement, Subcommittee on Febrile Seizures. Pediatrics 1996;97:769-75.

84 Warden CR, Zibulewsky J, Mace S, et al. Evaluation and management of febrile seizures in the out-of-hospital and emergency department settings. Ann Emerg Med 2003:41:215-22.

85 Chamberlain JM, Gorman RL. Occult bacteraemia in children with simple febrile seizures. Am J Dis Child 1988;142:1073-6.

86 Offringa M, Moyer VA. Evidence based paediatrics: evidence based management of seizures associated with fever. BMJ 2001;323:111-14

87 Heiibel J, Blom S, Bergfors PG. Simple febrile convulsions: a prospective incidence study and an evaluation of investigations initially needed. Neuropediatrics 1980;11:45-56.

88 Joffe A, McCormick M, DeAngelis C. Which children with febrile seizures need lumbar puncture? A decision analysis approach. Am J Dis Child 1983;137:153-6.

89 Rossi LN, Brunelli G, Duzioni N, et al. Lumbar puncture and febrile convulsions. Helv Paediat Acta 1986;41:19-24.

90 Rutter N, Smales ORC. Role of routine investigations in children presenting with their first febrile convulsion. Arch Dis Child 1977:52:188-91.

91 Green SM, Rothrock SG, Clem KJ, et al. Can seizures be the sole manifestation of meningitis in febrile children. Pediatrics 1993;92:527-34

92 Mclntyre PB, Gray SV, Vance JC. Unsuspected bacterial infections in febrile convulsions. Med J Aust 1990;152:183-6.

93 Joint Working Group of the Research Unit of the Royal College of Physicians and the British Paediatric Association. Guidelines for the management of convulsions with fever. BMJ 1991;303:634-6.

94 Baram TZ, Shinnar S, eds. Febrile seizures. San Diego: Academic Press, 2002.

95 Kneen R, Solomon T, Appleton RE. The role of lumbar puncture in suspected CNS infection-a disappearing skill? Arch Dis Child 2002;87:181-3.

96 Carroll W, Brookfield D. Lumbar puncture following febrile convulsion. Arch Dis Child 2002;87:238-40.

97 Camfield PR, Camfield CS. Febrile seizures. In: Ross EM, Woody RC, eds. Bailliere's clinical paediatrics. London: Bailliere Tindal, 1994:547-9.

98 Fukuyama Y, Seki T, Ohtsuka C, et al. Practical guidelines for physicians in the management of febrile seizures. Brain Dev 1996;18:479-84.

99 Maytal J, Steele R, Eviatar L, et al. The value of early postictal EEG in children with complex febrile seizures. Epilepsia 2000;41:219-21.

100 Baumann RJ, Duffner PK. Treatment of children with simple febrile seizures: the AAP practice parameter. American Academy of Pediatrics. Pediatr Neurol 2000;23:11-17.

101 Knudsen FU. Febrile seizures: treatment and prognosis. Epilepsia 2000;41:2-9

102 Rosman NP, Colton T, Labazzo J, et al. A controlled trial of diazepam administered during febrile illnesses to prevent recurrence of febrile seizures. N Engl J Med 1993;329:79-84.

103 Knudsen FU, Vestermark S. Prophylactic diazepam or phenobarbitone in febrile convulsions: a prospective, controlled study. Arch Dis Child 1978;53:660-3

104 Newton RW. Randomised controlled trials of phenobarbitone and valproate in febrile convulsions. Arch Dis Child 1988;63:1189-91.

105 Rantala H, Tarkka R, Uhari M. A meta-analytic review of the preventive treatment of recurrences of febrile seizures. J Pediatr 1997;131:922-5.

106 Antony JH, Hawke SH. Pentobarbital compared with carbamazepine in prevention of recurrent febrile convulsions. A double blind study. Am J Dis Child 1983;137:892-5

107 van Stuijvenberg $M$, de Vos S, Tjiang GC, et al. Parents' fear regarding fever and febrile seizures. Acta Paediatr 1999;88:618-22.

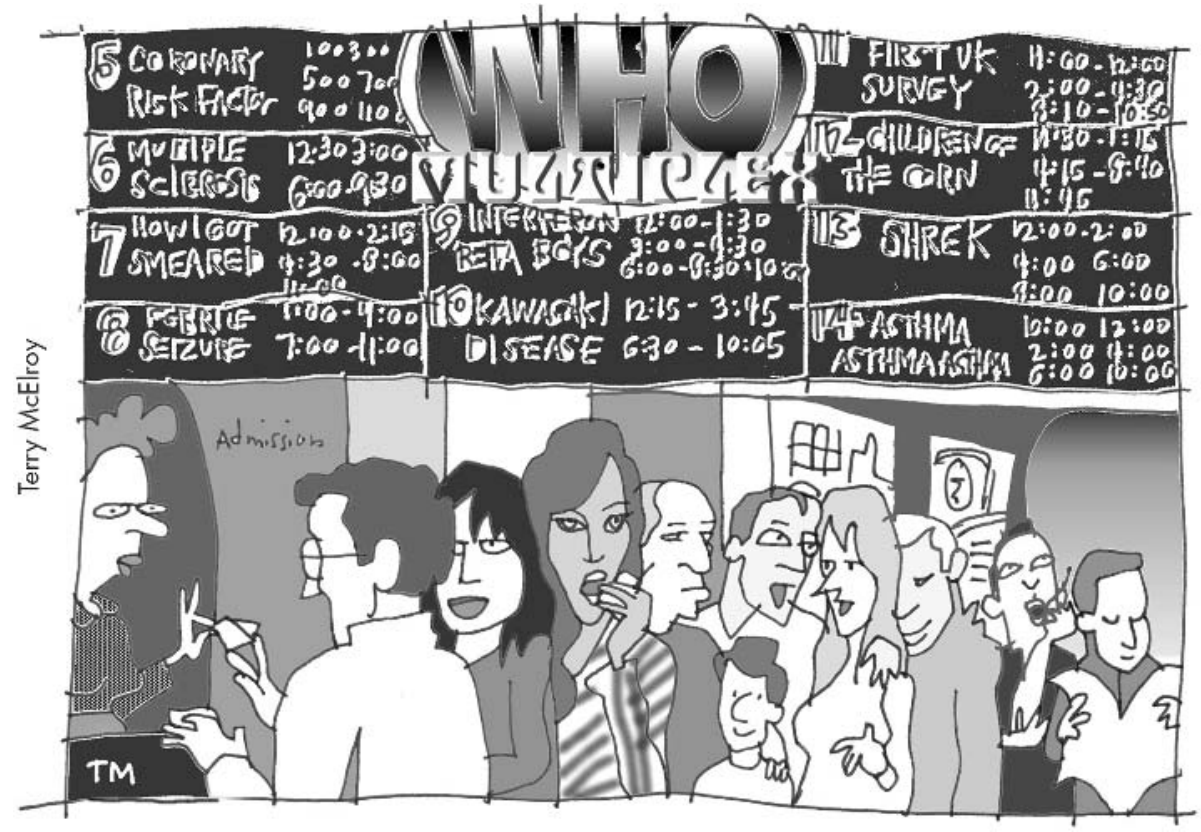

